\title{
Patient's travel distance to specialised cancer diagnostics and the association with the general practitioner's diagnostic strategy and satisfaction with the access to diagnostic procedures: an observational study in Denmark
}

Line Flytkjær Virgilsen ${ }^{1,2^{*}}$ (D) Line Hvidberg ${ }^{3}$ and Peter Vedsted ${ }^{1,2}$

\begin{abstract}
Background: Research indicate that when general practitioners (GPs) refer their patients for specialist care, the patient often has long distance. This study had a twofold aim: in accordance to the GP's suspicion of cancer, we investigated the association between: 1) cancer patient's travel distance to the first specialised diagnostic facility and the GP's diagnostic strategy and 2) cancer patient's travel distance to the first specialised diagnostic facility and satisfaction with the waiting time and the availability of diagnostic investigations.

Method: This combined questionnaire- and registry-based study included incident cancer patients diagnosed in the last 6 months of 2016 where the GP had been involved in the diagnostic process of the patients prior to their diagnosis of cancer $(n=3455)$. The patient's travel distance to the first specialised diagnostic facility was calculated by ArcGIS Network Analyst. The diagnostic strategy, cancer suspicion and the GP's satisfaction with the waiting times and the available investigations were assessed from GP questionnaires.

Results: When the GP did not suspect cancer or serious illness, an insignificant tendency was seen that longer travel distance to the first specialised diagnostic facility increased the likelihood of the GP using 'wait-and-see' approach and 'medical treatment' as diagnostic strategies. The GPs of patients with travel distance longer than 49 $\mathrm{km}$ to the first specialised diagnostic facility were more likely to report dissatisfaction with the waiting time for requested diagnostic investigations (PR: 1.98, 95\% Cl: 1.20-3.28).

(Continued on next page)
\end{abstract}

\footnotetext{
* Correspondence: line.virgilsen@ph.au.dk

${ }^{1}$ Research Unit for General Practice, Aarhus, Bartholins Allé 2, 8000 Aarhus C, Denmark

${ }^{2}$ Research Centre for Cancer Diagnosis in Primary Care (CaP), Department of Public Health, Aarhus University, Bartholins Allé 2, 8000 Aarhus C, Denmark

Full list of author information is available at the end of the article
}

C C The Author(s). 2020 Open Access This article is licensed under a Creative Commons Attribution 4.0 International License, which permits use, sharing, adaptation, distribution and reproduction in any medium or format, as long as you give appropriate credit to the original author(s) and the source, provide a link to the Creative Commons licence, and indicate if changes were made. The images or other third party material in this article are included in the article's Creative Commons licence, unless indicated otherwise in a credit line to the material. If material is not included in the article's Creative Commons licence and your intended use is not permitted by statutory regulation or exceeds the permitted use, you will need to obtain permission directly from the copyright holder. To view a copy of this licence, visit http://creativecommons.org/licenses/by/4.0/ The Creative Commons Public Domain Dedication waiver (http://creativecommons.org/publicdomain/zero/1.0/) applies to the data made available in this article, unless otherwise stated in a credit line to the data. 
(Continued from previous page)

Conclusion: A insignificant tendency to use 'wait-and-see' and 'medical treatment' were seen among GPs of patients with long travel distance to the first diagnostic facility when the GP did not suspect cancer or serious illness. Long distance was associated with higher probability of GP dissatisfaction with the waiting time for diagnostic investigations.

Keywords: General practice, Travel distance, Diagnostic strategy, GP satisfaction, Cancer, Early diagnosis, Denmark

\section{Background}

Western healthcare systems have increasingly centralised and specialised healthcare services over the recent decades [1, 2]. Travel distance to medical consultations and accessibility of GPs are central topics in many healthcare systems due to shortage of GPs and increasing centralisation. Further, in countries with a gatekeeping system, GPs may have to consider long distances when referring patients to specialised care [1-5].

The literature is inconclusive on the potential impact of distance to diagnostic services on cancer outcomes. Some studies have suggested that longer distance to healthcare services or rural residence are associated with poorer cancer prognosis [6-9]. Others have reported better prognosis in patients with long distance to healthcare services or rural residence $[10,11]$. Some studies have found no association $[12,13]$. Our research group has found that the association between distance to cancer diagnostics and diagnostic delays in the cancer trajectory depends on the diagnostic difficulty of the underlying cancer [14]. Other studies, including a few qualitative studies, have attempted to establish the direction and the magnitude of the impact of distance on cancer outcomes $[15,16]$, but possible explanations remain understudied.

GPs play a crucial role in early cancer detection because the majority of cancer patients initially consult their GP with symptoms $[17,18]$. In approximately $50 \%$ of patients who begin the diagnostic journey in general practice, the GP will suspect cancer at the first presentation [19], and the suspicion is more often raised when the patient present with alarm symptoms [19, 20]. The GP often has a range of strategies available for further relevant diagnostics including in-house options as "waitand-see", blood tests and medical treatment such as prescription medicine. The GP can also act as a gatekeeper to e.g. specialised private practices, Cancer Patient Pathways (CPP) or diagnostic imaging (e.g. CT scan). Therefore, the actions taken by the GP upon the patient's symptom presentation may considerably affect the cancer trajectory [17]. Nevertheless, it is unknown if the GP's diagnostic strategy is affected by the patient's travel distance to the medical facility performing cancer diagnostic investigations. Furthermore, we do not know whether this travel distance may affect the GP's satisfaction with the access to and waiting time for diagnostic investigations.
The aim of this study was twofold: in accordance to the GP's suspicion of cancer, we investigate the association between 1) cancer patient's travel distance to the first specialised diagnostic facility and the GP's diagnostic strategy and 2) cancer patient's travel distance to the first specialised diagnostic facility satisfaction with the waiting time and the availability of diagnostic investigations.

\section{Methods}

\section{Study design and setting}

This nationwide observational study based on combined questionnaire- and registry data was conducted in Denmark with a population of 5.8 million in 2018. The healthcare system is tax-funded and offers free access to healthcare for all citizens. The GP acts as a gatekeeper serving as the first point of contact to the healthcare system, and $99 \%$ of the Danish population is registered with a general practice, which must be consulted for medical advice [21]. GPs can refer patients to investigations and treatment at hospitals and private practicing specialists. CPPs have been implemented for more than 30 types of cancer to ensure standardised national guidelines on the diagnostics and treatment of cancer [22].

\section{Participants}

The study population was defined as patients aged 3099 years recorded with an incident cancer diagnosis (excluding ICD-10: C44) between 1 July and 20 December 2016 in the Danish National Patient Register (NPR) [23].

Patients were eligible if a first registered cancer related investigation could be assessed in Danish nationwide registers and two data sources were used. First, patients undergoing a first diagnostic investigation at a specialised private practice (gynaecology, ear-nose-throat specialist, eye specialist or dermatologist) were identified in the National Health Insurance Service Register (NHISR) (specialty codes: 04, 07, 15, 16, 19, 21, 39, 41). These specialties serve as filter functions in a number of CPPs often referred by a GP. Contacts up to 3 months prior to diagnosis were assessed in the NHISR, and the first registered contact in this period was selected. Second, patients for whom no diagnostic investigations had been recorded in the NHISR were identified through hospital contacts recorded in the NPR [23]. We identified 
contacts to the hospital for up to 3 months prior to the date of diagnosis and selected the first relevant contact (an ICD-10 DC or DZ code, excluding Z08-Z09, Z20Z29, Z30-Z39, Z55-Z65, Z70-Z76).

The GPs of the included patients received a questionnaire between 28 April 2017 and 10 January 2018 for each patient who had given consent to contact their GP. If the patient had deceased shortly after the diagnosis, permission to contact was granted by the Danish Patient Safety Authority [24]. As the cancer was diagnosed up to $1 \frac{1}{2}$ year before the GP received the questionnaire, it was emphasised that the GP should fill in the questionnaire based on the medical records. The questionnaire focussed on the following themes: milestone dates in the cancer trajectory, diagnostic strategy, routes to diagnosis and satisfaction with diagnostic procedures [25]. A GP could fill in questionnaires for more than one patient.

The inclusion criteria were: 1) the GP had completed the questionnaire, 2) the GP was involved in the diagnostic process. Thus, GP responses of 3455 patients were eligible for inclusion in the study.

\section{Data sources}

All data sources were linked through the patient's unique civil registration number (CRN), which is allocated to all Danish residents and used at every contact with the healthcare system [26]. Information on the GP's diagnostic strategy and level of satisfaction with diagnostic investigations was obtained from the GP questionnaire.

\section{Variables}

Diagnostic strategy of the GP was assessed from the GP questionnaire where the GP was asked, "Which actions did you/your practice take in the time from when the patient first contacted your practice until you/your practice referred the patient for further investigations for the first time?" The following response options were included in the questionnaire as an option: 1) wait-and-see approach (yes/no), 2) medical treatment (yes/no) and 3) referral to further diagnostic investigation on the same day (yes/no). Referral can either be to a CPP, diagnostic unit, specialised private practice, diagnostic imaging or other laboratory test at the hospital. For this study, referral was investigated in general terms and not distinguished between different referral modalities as this depend on e.g. the patients symptoms and the GPs options for referral.

Satisfaction with waiting time and available diagnostic investigations was assessed from the two following questions in the GP questionnaire: "How satisfied were you with the availability of diagnostic investigations?" and "How satisfied were you with the waiting time for diagnostic investigations?" The response categories "very satisfied" and "satisfied" were combined into "satisfied", and "dissatisfied" and "very dissatisfied" were combined into "dissatisfied". The response category "do not know/ not relevant" was omitted. The availability of diagnostic investigations vary across regions in Denmark and the GP answered these questions based on his or her availability.

Travel distance (shortest road distance) between patient's residential address on the date of diagnosis and the diagnostic facility where the first diagnostic investigation took place in the cancer trajectory was calculated by ArcGIS Network Analyst [27]. This information was obtained from the Danish Civil Registration System [26]. Distance to the first diagnostic facility was calculated for 3231 patients (first contact to a hospital: 87\%; first contact to a specialised private practice: $13 \%$ ). To avoid possible outliers or inclusion of erroneous registrations, it was chosen to exclude patients with a distance of more than $100 \mathrm{~km}$ to the first diagnostic facility $(n=76)$, as it is unlikely in Denmark that the first relevant diagnostic investigation is so far from the patients residence. Thus, 3155 patients were included in the analysis.

\section{Confounders}

The following variables were included as potential confounders based on data from Statistics Denmark: age, sex, patient's education categorised according to UNESCO's International Standard Classification of Education [28] (low: $\leq 10$ years, middle: $>10 \leq 15$ years and high: > 15 years) and patient's marital status (married/cohabiting or living alone). Information on cancer type was obtained from the NPR and included as a potential confounder categorised into: 1) breast cancer, 2) gynaecological cancer, 3) cancer in male genitals, 4) cancer in the digestive organs, 5) cancer in the respiratory system, 6) malignant melanoma, 7) haematological cancer or lymphomas and 8) other types of cancer.

\section{Statistical analysis}

Generalised linear models (GLMs) with prevalence ratios (PRs) and 95\% confidence intervals (CI) were applied to study the association between travel distance from patient's residence to the first specialised diagnostic facility and the GP's diagnostic strategy and satisfaction with availability for diagnostic investigations. Distance to the medical facility performing the first specialised diagnostic investigation was categorised into the $25,50,75$ and $90 \%$ centiles, corresponding to $0-6 \mathrm{~km},>6-18 \mathrm{~km},>$ $18-34 \mathrm{~km},>34-49 \mathrm{~km}$ and $>49 \mathrm{~km}$.

As the association between travel distance to the first diagnostic facility and the GP's diagnostic strategy interacted with the GP's suspicion of cancer, these analyses were presented stratified based on whether the GP suspected cancer or not. 
For both the analysis on the GP's diagnostic strategy and on satisfaction with the waiting time, the results were presented unadjusted followed by a model adjusting for patient's sex, age, education, marital status and cancer type. Prior to this, it was tested if distance was associated with the GPs suspicion of cancer or serious illness, which was not the case.

Stata statistical software, release 15.0, was used for all analyses.

\section{Results}

\section{Participants and descriptive data}

Among the 3155 included patients, the median age was 70 years, the majority were male, had middle-level education and were married (Table 1). The GP suspected cancer or serious illness in $64 \%$ of the patients at first presentation. Half of the patients lived within $18 \mathrm{~km}$ of the medical facility performing their first specialised diagnostic investigation (Table 1).

\section{Outcome: patient's travel distance and GP's diagnostic strategy}

When the GP did not suspect cancer, there was an insignificant tendency that travel distance of more than $6 \mathrm{~km}$ to the patient's first diagnostic cancer investigation was associated with higher likelihood of the GP selecting 'wait-and-see' and 'medical treatment' as diagnostic strategy. However, this was only statistically significant in the distance category $>6-18 \mathrm{~km}$ for 'wait-and-see' and in the category $>18-34 \mathrm{~km}$ for 'medical treatment' (Table 2).

\section{Outcome: patient's travel distance and GP's satisfaction with investigations}

GPs of patients with a distance of more than $49 \mathrm{~km}$ to the first diagnostic facility were more likely to report dissatisfaction with the waiting time for diagnostic investigations ( $\left.\mathrm{PR}_{\mathrm{adj}} 1.98,95 \% \mathrm{CI}: 1.20-3.28\right)$. There was also a not statistically significant tendency that GPs of patients with a distance of more than $49 \mathrm{~km}$ to the first diagnostic facility were more likely to report dissatisfaction with the availability of diagnostic investigations (Table 3 ).

\section{Discussion}

\section{Key results}

When GPs did not suspect cancer or serious illness at first presentation, there was an insignificant tendency that patient's travel distance to the first diagnostic cancer investigation was associated with the GP using 'waitand-see' or 'medical treatment' as initial diagnostic strategy. Furthermore, when the patient's travel distance to the first specialised diagnostic facility exceeded $49 \mathrm{~km}$, lower GP satisfaction was seen with the waiting time for GP-requested diagnostic investigations.
Table 1 Socio-economic position and patient's travel distance to first specialised cancer facility in the study population (numbers vary due to missing data)

\begin{tabular}{lll}
\hline & $\mathrm{N}$ & $(\%)$ \\
\hline Total & 3155 & $(100)$ \\
Age, median (IQR) & $70(61-76)$ & \\
Sex & & \\
$\quad$ Female & 1507 & $(47.8)$ \\
$\quad$ Male & 1648 & $(52.2)$ \\
Education & & \\
$\quad$ Low & & \\
$\quad$ Middle & 996 & $(32.4)$ \\
High & 1399 & $(45.5)$ \\
& 678 & $(22.1)$
\end{tabular}

\section{Marital status}

Married/cohabiting 1976

Living alone

GP's suspicion of cancer or serious illness

No

Yes

\section{Cancer type}

Breast cancer
Gynaecological cancer
Cancer in the male genitals
Cancer in the digestive system
Cancer in the respiratory system
Haematological cancer and lymphomas
Malignant melanoma
Others

Distance $^{\mathrm{a}}(\mathrm{km})$, median (IQR)

Distance $^{\mathrm{a}}(\mathrm{km})$ categorical

$\begin{array}{lll}0-6 & 785 & (25.0) \\ >6-18 & 778 & (24.7) \\ >18-34 & 778 & (24.7) \\ >34-49 & 493 \\ >49 & 321\end{array}$

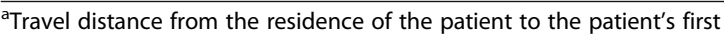
specialised cancer facility

\section{Strengths and limitations}

The assessment of the GP's diagnostic strategy and the level of satisfaction was based on responses from a national questionnaire survey among GPs of newly diagnosed patients, and the identification of patients was based on the NPR, which is known to have valid and complete data [23]. The GPs were asked to check their medical records when responding to the questionnaire. Hence, even though the questionnaire was answered in retrospect and some $1 \frac{1 / 2}{2}$ years after the cancer diagnosis was given, the risk of recall bias was minimised. The 
Table 2 The association between patient's travel distance to first specialised diagnostic facility and the probability of the GP using "wait-and-see", "medical treatment" and "referral the same day"(i.e. the diagnostic strategy of the GP) stratified on whether the GP suspected cancer or serious illness or not

\begin{tabular}{|c|c|c|c|c|c|c|}
\hline & \multicolumn{2}{|l|}{ Wait-and-see ${ }^{\mathbf{b}}$} & \multicolumn{2}{|l|}{ Medical treatment ${ }^{\mathbf{b}}$} & \multicolumn{2}{|c|}{ Referred the same day ${ }^{\mathbf{b}}$} \\
\hline & $\begin{array}{l}\text { GP did suspect } \\
\text { cancer or serious } \\
\text { illness } \\
(\boldsymbol{n}=2013)\end{array}$ & $\begin{array}{l}\text { GP did } \text { not suspect } \\
\text { cancer or serious } \\
\text { illness } \\
(\boldsymbol{n}=1084)\end{array}$ & $\begin{array}{l}\text { GP did suspect } \\
\text { cancer or serious } \\
\text { illness } \\
(\boldsymbol{n}=2013)\end{array}$ & $\begin{array}{l}\text { GP did } \text { not suspect } \\
\text { cancer or serious } \\
\text { illness } \\
(\boldsymbol{n}=1084)\end{array}$ & $\begin{array}{l}\text { GP did suspect } \\
\text { cancer or serious } \\
\text { illness } \\
(\boldsymbol{n}=2013)\end{array}$ & $\begin{array}{l}\text { GP did } \text { not suspect } \\
\text { cancer or serious } \\
\text { illness } \\
(\boldsymbol{n}=1084)\end{array}$ \\
\hline & $\mathrm{PR}_{\mathrm{adj}}(95 \% \mathrm{Cl})$ & PRadj $(95 \% C l)$ & PR adj $(95 \% \mathrm{Cl})$ & $\mathrm{PR}_{\mathrm{adj}}(95 \% \mathrm{Cl})$ & $\mathrm{PR}_{\mathrm{adj}}(95 \% \mathrm{Cl})$ & $\mathrm{PR}_{\mathrm{adj}}(95 \% \mathrm{Cl})$ \\
\hline \multicolumn{7}{|c|}{ Distance $^{\mathrm{a}}(\mathrm{km})$} \\
\hline $0-6$ & 1 (ref.) & 1 (ref.) & 1 (ref.) & 1 (ref.) & 1 (ref.) & 1 (ref.) \\
\hline$>6-18$ & $0.95(0.45-1.91)$ & $1.48(1.08-2.04)$ & $0.92(0.51-1.64)$ & $1.25(0.91-1.72)$ & $0.97(0.90-1.04)$ & $0.82(0.63-1.08)$ \\
\hline$>18-34$ & $0.84(0.42-1.67)$ & $1.15(0.82-1.61)$ & $0.88(0.47-1.58)$ & $1.45(1.05-1.99)$ & $0.99(0.92-1.06)$ & $0.84(0.64-1.12)$ \\
\hline$>34-49$ & $0.44(0.16-1.19)$ & $1.19(0.84-1.70)$ & $1.09(0.58-2.04)$ & $1.29(0.89-1.87)$ & $1.04(0.97-1.12)$ & $0.86(0.62-1.19)$ \\
\hline$>49$ & $1.21(0.52-2.79)$ & $1.21(0.81-1.82)$ & $1.05(0.50-2.21)$ & $1.29(0.88-1.91)$ & $1.01(0.92-1.11)$ & $1.07(0.78-1.46)$ \\
\hline
\end{tabular}

Analysis were based on 3097 patients, due to missing responses regarding GP's suspicion of cancer

${ }^{a}$ Travel distance from the residence of the patient to the first specialised facility

${ }^{\mathrm{b}}$ Adjusted for sex, age (continuous), education, marital status and cancer type

inclusion of GPs was determined by patients approving the inclusion of their GP in the study, except for GPs with patients who had deceased shortly after the diagnosis. It is likely that non-responding patients were more likely to have lower socio-economic status (SEP). GPs of patients with low SEP might thus have been be less representative in the study. Still, this has been shown not to bias outcome estimates markedly [29].

We used valid and complete registers to obtain information on SEP and cancer type of the patients [30]. The first diagnostic facility was also based on registry information from hospitals [23] and specialised private practices [31]; this information was identified in the registers based on an algorithm assessing contacts in the healthcare system 3 months prior to the diagnosis. Misclassification cannot be ruled out as the first diagnostic investigation might have been performed prior to this period. As the patient's travel distance and the GP's diagnostic strategy and satisfaction level are unknown for this group, it is not straightforward to predict the potential bias. We believe that the group affected by this potential bias is minimal, as previous work has found that $75 \%$ of all cancer patients are diagnosed within 73 days of first referral [32].

In cases where the patient is referred to a CPP including a filter function (e.g. gynaecological CPPs), the referral is organised in a central administration and the GP may not know which hospital or practice the patient is referred to ( $13 \%$ of the population). Hence, as the patient's travel distance is unknown to the GP, the diagnostic strategy cannot be influenced by this knowledge. This is most likely to occur in larger cities where several

Table 3 The association between patient's travel distance to the first diagnostic facility and the probability of the GP being dissatisfied with diagnostic investigations

\begin{tabular}{|c|c|c|c|c|c|c|}
\hline & \multicolumn{6}{|c|}{ GP's dissatisfaction with: } \\
\hline & \multicolumn{3}{|c|}{ Availability of diagnostic investigations } & \multicolumn{3}{|c|}{ Waiting time for diagnostic investigations } \\
\hline & $\mathrm{N}_{\text {dissatisfied }}$ & $\mathrm{PR}_{\text {unadj }}$ & $\mathrm{PR}_{\mathrm{adj}} \mathrm{b}^{\mathrm{s}}$ & $\mathrm{N}_{\text {dissatisfied }}$ & $\mathrm{PR}_{\text {unadj }}$ & $\mathrm{PR}_{\mathrm{adj}}^{\mathrm{b}}$ \\
\hline \multicolumn{7}{|c|}{ Distance $^{\mathrm{a}}(\mathrm{km})$} \\
\hline $0-6$ & 17 & 1 (ref.) & 1 (ref.) & 33 & 1 (ref.) & 1 (ref.) \\
\hline$>6-18$ & 15 & $0.89(0.45-1.77)$ & $0.91(0.46-1.80)$ & 43 & $1.33(0.86-2.07)$ & $1.33(0.85-2.08)$ \\
\hline$>18-34$ & 9 & $0.52(0.23-1.16)$ & $0.58(0.26-1.30)$ & 28 & $0.87(0.53-1.42)$ & $0.90(0.55-1.49)$ \\
\hline$>34-49$ & 8 & $0.74(0.32-1.70)$ & $0.89(0.38-2.06)$ & 21 & $1.00(0.59-1.71)$ & $1.07(0.62-1.84)$ \\
\hline$>49$ & 12 & $1.72(0.83-3.56)$ & $1.89(0.90-3.85)$ & 24 & $1.86(1.12-3.09)$ & $1.98(1.20-3.28)$ \\
\hline
\end{tabular}

a Travel distance from the residence of the patient to the first specialised investigation

${ }^{b}$ Adjusted for sex, age (continuous), education, marital status, cancer type and cancer type 
e.g. gynaecologists practice medicine, and the GP therefore do not know which of the specialised practices the patient would be referred to by the central administration. However, the patient's distance would most likely not vary substantial since most specialised practices is located rather central. Further, a sensitivity analysis indicated similar results when we excluded cases often diagnosed through a CPP using filter functions (gynaecological cancer, ear-nose-throat cancer, eye cancer or malignant melanoma) (data not shown).

The study did not distinguish between which type of referral the GP applied (e.g. CPP, imaginal diagnostic at the hospital etc.), but classified "referral for further diagnostics on the first day" as one. This was chosen due to considerations about sample size and because the available diagnostic investigations vary somewhat across the regions and hospitals in Denmark. Thus, not all GPs have direct access to $\mathrm{CT}$ scan and data was not available on which investigations each GP had access too. It could have provided further insights if this data was available, as the GPs perception on access to available investigations and waiting time hereof is likely to reflect their reality and this could therefore potentially influence the time to diagnosis. All GPs can however refer to CPP's, and it could further be interesting to assess if distance modified the use of CPP.

We adjusted for cancer type as a proxy of the underlying symptom(s) presented by the patient, as this information was not available in the data. However, this approach could be linked with insecurity as symptoms vary within each cancer type.

High celling effect was seen for some of the responses, and few responses were available in some of the categories. Consequently, type II errors cannot be ruled out (e.g. in the stratified analysis on 'wait-and-see' and 'medical treatment'). This could explain why the findings did not reach statistical significance for all categories in these analyses. Consequently, the results should be interpreted with caution and larger-scale studies are required to establish an association. However, to our knowledge no other studies have been carried out to study how distance is associated with the GP's diagnostic strategies and this study indicate that GP's of patient with longer distance to further cancer diagnostics more often use "wait-and-se" and "medical treatment" if cancer or serious illness is not the first suspicion of the GP.

\section{Interpretation}

Previous studies have investigated factors of importance for the GP's propensity to refer patients for cancer diagnostics. The literature suggests that important factors for the GP's choice of action at first consultation include organisational factors, such as funding system and access to investigations, and contextual factors, such as symptomology and relationship with specialist colleagues $[5,19,33]$. Thus, the diagnostic strategy of the GP, including direct referral or wait-and-see, appears to be multifaceted and to depend on the specific healthcare system, as suggested by a recent study [5].

A study from 2018 combining results on GP referral modalities in 20 countries found that the GPs in $56 \%$ of the responding countries agreed that their patients often had to travel long distances to consult a medical specialist [5], but it remains unclear how increasing travel distance to specialist medical care may affect cancer outcomes [6-13].

Few studies have explored underlying factors behind the potential association between travel distance and cancer outcome $[15,16]$. To our knowledge, this is the first study to investigate how the patient's travel distance to the first diagnostic facility influences the GP's diagnostic strategy. Thereby, it is also one of the first studies attempting to investigate how the patient's travel distance and related underlying mechanisms may influence cancer outcome. When stratifying the analysis on the GP's suspicion of cancer, we found an insignificant tendency that increasing travel distance for the patient was associated with increasing use of 'wait-and-see' and 'medical treatment' when the GP did not suspect cancer. It is a positive factor that the GP's diagnostic strategy was not influenced by patient's travel distance when the GP did suspect cancer. However, although the results were ambiguous, the insignificant tendency for GPs to use 'wait-and-see' for patients with increasing distance to cancer diagnostic facilities indicates that GPs may indeed be affected by the distance to a relevant cancer facility. As all of these patients did turn out to have cancer, this finding should be elaborated further in larger studies.

Increasing travel distance to the patient's first diagnostic facility was associated with higher GP dissatisfaction with the waiting time for requested diagnostic investigations. This was only found for GPs with patients having more than $49 \mathrm{~km}$ between their residential address and the medical facility performing the diagnostic investigation; this could suggest signs of barriers in general practices remotely located from large hospitals. A recent study among GPs in 20 European countries found that rural GPs perceive lower access to diagnostic modalities and the GP perceived more patient related barriers for specialist accessibility [34] which support the findings of dissatisfaction among GPs with increased distance to specialised diagnostics. This dissatisfaction might be rooted in communication barriers between primary and secondary care. Previous studies have pointed to the importance of well-established communication between primary and secondary care for optimal diagnostics [3537]. As the GP answered the question on satisfaction 
based on the availability of services in their own practice, this could explain the high rate of dissatisfaction among GPs with long distance who according to the results also tended to be more likely to manage their patients with a wait-and-see strategy if cancer was not suspected. Thus, this could be patients with no alarming symptoms whose GP has the perception of low availability of services, i.e. distant services, which are also distant from the patient's residence. However, further studies are needed to explore if the findings in the present study are linked to communication barriers or other factors affecting the GP's perception of waiting time. These studies should also take into account the variability in referral options for the GPs. E.g. not all Danish GPs have the possibility to refer directly to CT scan. It is unknown how this affect the GP's assessment of available investigations.

\section{Conclusion}

This study found an insignificant tendency for GPs to use 'wait and see' and 'medical treatment' as diagnostic strategy when cancer or serious illness was not suspected in patients with long travel distance to the medical facility performing the first diagnostic investigation. Longer distance was associated with higher GP dissatisfaction with the waiting time for diagnostic investigations. Further studies with larger samples are required to establish the association.

\section{Abbreviations}

Cl: Confidence interval; CPP: Cancer patient pathway; CRN: Civil registration number; GDPR: General Data Protection Regulation; GLM: Generalised linear models; GP: General practitioner; ICD-10: International Classification of Diseases, 10th revision; NHISR: (Danish) National Health Insurance Service Register; NPR: (Danish) National Patient Register; PR: Prevalence ratio; SEP: Socio-economic position

\section{Acknowledgements}

Not Applicable.

\section{Authors' contributions}

LFV, LH and PV conceived the idea and contributed with input, interpretations of the results and the contents of the paper. LFV was responsible for drafting the manuscript and for the statistical analyses. All authors read and approved the final version of the manuscript.

\section{Funding}

This project was funded by the Danish Cancer Society and the Health Foundation (Danish: Helsefonden). The funding sources were not involved in the planning or conduction of the analysis, interpretation of results or writing of the paper.

\section{Availability of data and materials}

Data used for this study is not public available according to Danish laws.

\section{Ethics approval and consent to participate}

According to Danish law, this study did not need approval by the Committee on Health Research Ethics as the study was based solely on questionnaire and registry data [38]. The project "Geographic variations and cancer outcomes" (ID 189) has been approved and is registered in the Record of Processing Activities at the Research Unit for General Practice in
Aarhus in accordance with the provisions of the General Data Protection Regulation (GDPR).

The patients signed a consent to contact their GP and collect information on the diagnostic process of the patients. In accordance with $\S 46$ of the Danish Health Act, the Danish Patient Safety Authority gave us permission to obtain information (by questionnaires) from the GPs' medical records for patients who deceased shortly after their diagnosis (case no. 3-3013-1956/1).

\section{Consent for publication}

Not applicable.

\section{Competing interests}

The authors declare that there are no conflicts of interests.

\section{Author details}

${ }^{1}$ Research Unit for General Practice, Aarhus, Bartholins Allé 2, 8000 Aarhus C, Denmark. ${ }^{2}$ Research Centre for Cancer Diagnosis in Primary Care (CaP), Department of Public Health, Aarhus University, Bartholins Allé 2, 8000 Aarhus C, Denmark. ${ }^{3}$ Department of Quality and Improvement, Hospital of South West Jutland, Finsensgade 35, 6700 Esbjerg, Denmark.

Received: 4 February 2020 Accepted: 17 May 2020

Published online: 31 May 2020

\section{References}

1. Olejaz M, Juul Nielsen A, Rudkjøbing A, Birk H, Krasnik A, HernándezQuevedo C. Denmark Health System review. Health Syst Transit. 2012;14(2): 1.

2. Micheli A, Coebergh JW, Mugno E, Massimiliani E, Sant M, Oberaigner W, Holub J, Storm HH, Forman D, Quinn M, et al. European health systems and cancer care. Ann Oncol. 2003;14(Suppl 5):v41-60.

3. Kelly C, Hulme C, Farragher T, Clarke G. Are differences in travel time or distance to healthcare for adults in global north countries associated with an impact on health outcomes? A systematic review. BMJ Open. 2016;6(11): e013059-012016-013059.

4. Majeed A. Shortage of general practitioners in the NHS. Bmj. 2017;358:j3191.

5. Harris M, Vedsted P, Esteva M, Murchie P, Aubin-Auger I, Azuri J, Brekke M, Buczkowski K, Buono N, Costiug E, et al. Identifying important health system factors that influence primary care practitioners' referrals for cancer suspicion: a European cross-sectional survey. BMJ Open. 2018;8(9):e022904.

6. Jones AP, Haynes R, Sauerzapf V, Crawford SM, Zhao H, Forman D. Travel times to health care and survival from cancers in northern England. Eur J Cancer. 2008;44(2):269-74.

7. Massarweh NN, Chiang YJ, Xing Y, Chang GJ, Haynes AB, You YN, Feig BW, Cormier JN. Association between travel distance and metastatic disease at diagnosis among patients with colon cancer. J Clin Oncol. 2014;32(9):942-8.

8. Campbell NC, Elliott AM, Sharp L, Ritchie LD, Cassidy J, Little J. Rural and urban differences in stage at diagnosis of colorectal and lung cancers. $\mathrm{Br} \mathrm{J}$ Cancer. 2001;84(7):910-4

9. Nguyen-Pham S, Leung J, McLaughlin D. Disparities in breast cancer stage at diagnosis in urban and rural adult women: a systematic review and meta-analysis. Ann Epidemiol. 2014;24(3):228-35.

10. Xu Z, Becerra AZ, Justiniano CF, Boodry Cl, Aquina CT, Swanger AA, Temple LK, Fleming FJ. Is the distance worth it? Patients with rectal Cancer traveling to high-volume centers experience improved outcomes. Dis Colon Rectum. 2017;60(12):1250-9.

11. Murage $P$, Murchie $P$, Bachmann $M$, Crawford $M$, Jones $A$. Impact of travel time and rurality on presentation and outcomes of symptomatic colorectal cancer: a cross-sectional cohort study in primary care. Br J Gen Pract. 2017; 67(660):e460-6.

12. Gunderson CC, Nugent EK, McMeekin DS, Moore KN. Distance traveled for treatment of cervical cancer: who travels the farthest, and does it impact outcome? Int J Gynecol Cancer. 2013;23(6):1099-103.

13. Hines RB, Markossian TW. Differences in late-stage diagnosis, treatment, and colorectal cancer-related death between rural and urban African Americans and whites in Georgia. J Rural Health. 2012;28(3):296-305.

14. Flytkjaer Virgilsen L, Moller H, Vedsted P. Cancer diagnostic delays and trave distance to health services: a nationwide cohort study in Denmark. Cancer Epidemiol. 2019;59:115-22. 
15. Bain NS, Campbell NC. Treating patients with colorectal cancer in rural and urban areas: a qualitative study of the patients' perspective. Fam Pract. 2000; 17(6):475-9.

16. Brundisini F, Giacomini M, DeJean D, Vanstone M, Winsor S, Smith A. Chronic disease patients' experiences with accessing health care in rural and remote areas: a systematic review and qualitative meta-synthesis. Ont Health Technol Assess Ser. 2013;13(15):1-33.

17. Allgar VL, Neal RD. General practictioners' management of cancer in England: secondary analysis of data from the National Survey of NHS patients-Cancer. Eur J Cancer Care. 2005;14(5):409-16.

18. Hansen RP, Vedsted P, Sokolowski I, Sondergaard J, Olesen F. Time intervals from first symptom to treatment of cancer: a cohort study of 2,212 newly diagnosed cancer patients. BMC Health Serv Res. 2011;11:284 6963-69116284.

19. Jensen $\mathrm{H}$, Torring ML, Olesen F, Overgaard J, Vedsted P. Cancer suspicion in general practice, urgent referral and time to diagnosis: a population-based GP survey and registry study. BMC Cancer. 2014;14:636.

20. Scheel BI, Ingebrigtsen SG, Thorsen T, Holtedahl K. Cancer suspicion in general practice: the role of symptoms and patient characteristics, and their association with subsequent cancer. Br J Gen Pract. 2013;63(614):e627-35.

21. Pedersen KM, Andersen JS, Sondergaard J. General practice and primary health care in Denmark. J Am Board Family Med. 2012;25(Suppl 1):S34-8.

22. Probst HB, Hussain ZB, Andersen O. Cancer patient pathways in Denmark as a joint effort between bureaucrats, health professionals and politicians-a national Danish project. Health policy (Amsterdam, Netherlands). 2012; 105(1):65-70.

23. Lynge E, Sandegaard JL, Rebolj M. The Danish National Patient Register. Scand J Public Health. 2011;39(7 Suppl):30-3.

24. The Danish Patient Safety Authority. Health professionals and authorities https://en.stps.dk/en/. Accessed 12 Apr 2020.

25. The Danish Cancer Society. Cancer patient's needs and experiences with the health care system during diagnostics and treatement [in Danish: Kræftpatienters behov og oplevelser med sundhedsvæsenet under udredning og behandling]. In. Copenhagen; 2017.

26. Pedersen CB. The Danish civil registration system. Scand J Public Health. 2011;39(7 Suppl):22-5

27. Esri. ArcGIS Network Analyst. https://www.esri.com/en-us/arcgis/products/ arcgis-network-analyst/overview. Accessed 12 Apr 2020

28. UNESCO: ISCED: International Standard Classification of Education. http://uis. unesco.org/en/topic/international-standard-classification-education-isced. Accessed 12 Apr 2020

29. Nohr EA, Frydenberg M, Henriksen TB, Olsen J. Does low participation in cohort studies induce bias? Epidemiology (Cambridge, Mass). 2006;17(4): 413-8.

30. Gjerstorff ML. The Danish Cancer registry. Scand J Public Health. 2011;39(7 Suppl):42-5.

31. Andersen JS, Olivarius Nde F, Krasnik A. The Danish National Health Service Register. Scand J Public Health. 2011;39(7 Suppl):34-7.

32. Jensen $H$, Torring $M L$, Olesen F, Overgaard J, Fenger-Gron M, Vedsted $P$. Diagnostic intervals before and after implementation of cancer patient pathways - a GP survey and registry based comparison of three cohorts of cancer patients. BMC Cancer. 2015;15(1):308 -015-1317-1317.

33. Mitchell E, Macdonald S, Campbell NC, Weller D, Macleod U. Influences on pre-hospital delay in the diagnosis of colorectal cancer: a systematic review. Br J Cancer. 2008;98(1):60-70.

34. Murchie P, Khor WL, Adam R, Esteva M, Smyrnakis E, Petek D, Thulesius H, Vedsted $\mathrm{P}$, McLernon D, Harris M. Influences of rurality on action to diagnose cancer by primary care practitioners - results from a Europe-wide survey in 20 countries. Cancer Epidemiol. 2020;65:101698.

35. Sampson R, Barbour R, Wilson P. The relationship between GPs and hospital consultants and the implications for patient care: a qualitative study. BMC Fam Pract. 2016;17:45

36. Farquhar MC, Barclay SI, Earl H, Grande GE, Emery J, Crawford RA. Barriers to effective communication across the primary/secondary interface: examples from the ovarian cancer patient journey (a qualitative study). Eur J Cancer Care (Engl). 2005;14(4):359-66.

37. Green T, Atkin K, Macleod U. Cancer detection in primary care: insights from general practitioners. Br J of Cancer. 2015;112:S41-9.

38. The National Committee on Health Research Ethics. The system of health research ethics committees. http://www.nvk.dk/english/the-system-ofhealth-research-ethics-committees. Accessed 12 Apr 2020.

\section{Publisher's Note}

Springer Nature remains neutral with regard to jurisdictional claims in published maps and institutional affiliations.
Ready to submit your research? Choose BMC and benefit from:

- fast, convenient online submission

- thorough peer review by experienced researchers in your field

- rapid publication on acceptance

- support for research data, including large and complex data types

- gold Open Access which fosters wider collaboration and increased citations

- maximum visibility for your research: over $100 \mathrm{M}$ website views per year

At BMC, research is always in progress.

Learn more biomedcentral.com/submissions 